\title{
BMJ Open Case-comparison study protocol for gauging effects of neighbourhood trends and sickness: examining the perceptions of transit-Induced gentrification in Prince George's County
}

\author{
Jennifer D Roberts (D) , ${ }^{1}$ Shadi O Tehrani, ${ }^{2}$ Roger Isom, Jr, ${ }^{1}$ Eric A Stone, ${ }^{1}$ \\ Micah L Brachman, ${ }^{3}$ Valerie Newsome Garcia ${ }^{4}$
}

To cite: Roberts JD, Tehrani S0, Isom, Jr R, et al. Case-comparison study protocol for gauging effects of neighbourhood trends and sickness: examining the perceptions of transitInduced gentrification in Prince George's County. BMJ Open 2020;10:e039733. doi:10.1136/ bmjopen-2020-039733

- Prepublication history and additional material for this paper are available online. To view these files, please visit the journal online (http://dx.doi org/10.1136/bmjopen-2020039733).

Received 24 April 2020 Revised 06 July 2020

Accepted 14 August 2020
Check for updates

(c) Author(s) (or their employer(s)) 2020. Re-use permitted under CC BY-NC. No commercial re-use. See rights and permissions. Published by BMJ.

For numbered affiliations see end of article.

Correspondence to Dr Jennifer D Roberts; jenrob@umd.edu

\section{ABSTRACT}

Introduction Impoverished neighbourhoods and communities of colour often bear the brunt of unintended transit-oriented development (TOD) impacts. These impacts have been known to come in the form of transitinduced gentrification $(T I G)$, a socioeconomic by-product of TOD defined as a phenomenon that occurs when the provision of transit service, particularly light rail transit (LRT), 'up-scales' nearby neighbourhood(s) and displaces existing residents. Consequently, TIG or even the perception of TIG can impact health outcomes (eg, anxiety) and social determinants of health (SDOH) (eg, crime).

Methods/Analysis In 2022, the purple line (PL), a 16.2 mile LRT line, is opening in Prince George's County, Maryland, a suburb of Washington, DC, comprised of over 80\% African American and Hispanic residents. By taking advantage of this natural experiment, we are proposing the GENTS (Gauging Effects of Neighborhood Trends and Sickness: Examining the Perceptions of Transit-Induced Gentrification in Prince George's County) Study in order to evaluate perceived TIG and associated health outcome and $\mathrm{SDOH}$ changes, at two points in time, among Prince George's County adults in a prospective case-comparison design during the pre-PL LRT period. Descriptive analysis and latent growth curve modelling will be used to examine these changes over time.

Ethics and Dissemination Ethics approval has been granted by the University of Maryland Institutional Review Board. The GENTS Study will identify temporal changes in perceived TIG, health outcomes and SDOH among case and comparison residents before the completion and operation of the PL LRT, an under researched period of TOD. The dissemination of GENTS Study findings will be able to address research questions and policy issues that are specifically tailored to PG County while also providing more effective procedural solutions for other regions undergoing TOD and TIG risks.

\section{INTRODUCTION}

Transit-oriented development in the USA

Although environmental justice is a movement addressing economic and health impacts of
Strengths and limitations of this study

- This study is the first to prospectively investigate the relationship between gentrification perception and health using a longitudinal research framework at the neighbourhood level.

- This natural experiment is one of only a few to investigate the relationship between perceived gentrification, health outcomes and social determinants of health in a community of colour.

- This study does not have a follow-up period. We intend to perform that examination in the coming years.

- In light of the COVID-19 pandemic, this study will primarily rely on the online environment for the recruitment of participants.

environmental inequality and racism, it also serves as a foundation for understanding why poor neighbourhoods and communities of colour often encounter transit inequities and bear the brunt of unintended transit-oriented development (TOD) impacts. ${ }^{1}$ TOD was introduced by city planners and designers as a solution to a variety of urban problems such as energy dependence, urban poverty, land consumption, traffic congestion and public health challenges. TOD initiatives serve as powerful tools for improving the quality of life by reducing automobile dependence and increasing accessibility to employment and other transit destinations. Emerging as a popular and influential planning concept, TOD includes a mix of commercial, residential and entertainment properties centred around or located near a transit station. ${ }^{2}$ In an effort to create walkable, dense, mixed-use and connected communities, TOD is an integration strategy for public transportation investments and land-use practices. ${ }^{3}$ 
Therefore, TOD projects have increased in number over the past few decades with the rapid expansion of rail transit, particularly light rail transit (LRT) systems, in cities throughout the USA, such as Atlanta, GA; Detroit, MI; Milwaukee, WI; Charlotte, NC and Salk Lake City, UT. $^{34}$

As a function of TOD growth, LRT use increased in passenger miles by $280 \%$ from 1990 to 2010 in the USA. ${ }^{56}$ LRT is characterised by electric trains running along fixed routes with dedicated track corridors and passenger boarding stations. ${ }^{7}$ With smaller cars than commuter trains and traffic signal priority to ease efficiency, LRT has greater utility for implementation in densely populated metropolitan areas. ${ }^{89}$ For many reasons (eg, mass transit expansion, urbanisation), LRT and overall public transit use increased among Americans and tend to be higher among African Americans, Hispanics or immigrants. ${ }^{1011}$ For example, 34\% of African American and $27 \%$ of Hispanic urban residents reported a daily or weekly use of public transit compared with only $14 \%$ of white residents. ${ }^{12}$ Also, foreign-born versus Americanborn (38\% vs 18\%) urban residents have been found to use public transportation at a higher rate. ${ }^{12}$ Possible reasons for higher transit use among these populations have included (1) a higher likelihood of living in large metropolitan areas where there tend to be more public transit options, (2) a higher likelihood of commuting to work, (3) a higher likelihood of living further away from jobs and (4) a lower likelihood to automobile access. ${ }^{12}$

\section{Economic and social impacts of TOD}

TOD creates conditions for private investments, newly built developments and higher accessibility. Several studies characterised TOD outcomes as promoting economic development, elevating property values and enhancing livable environments. ${ }^{13-17}$ For example, research examining the housing premium associated with TOD in San Diego, CA found that a condo in a pedestrian-oriented environment and near a TOD, specifically a LRT station, had a significantly higher value than a condo in a similar neighbourhood and not near a LRT station. ${ }^{15}$ In an effort to rationalise wide-ranging results of empirical estimates, a meta-analysis using data drawn from 23 studies found that the price of properties near LRT increased by $8 \%$ and reached an upper limit range of $40 \% .{ }^{18}$ Another study also found that proximity to Phoenix, AZ LRT stations had a significant impact on housing values even before the actual LRT operations. ${ }^{19}$ Furthermore, some health and well-being benefits are positively associated with TOD and namely LRT use. This has included reduced traffic crashes and air pollution emissions, increased physical activity through active transportation and improved access to medical care and healthy food options. ${ }^{17} 2021$ Along with these positive benefits, the negative impacts of TODs are also recognised.

TODs can ignite a 'back-to-the-city' influx of highincome households due to the mixed land use, walkability and increased transit accessibility that results from these developments. ${ }^{1322}$ In the USA, particularly since the surge of suburbanisation in the $1950 \mathrm{~s}$, the ideologies, practices and policies of racially and economically based residential segregation have catalysed a cyclical oscillation of 'White Flight' from urban to suburban or suburban to urban areas. Although the social trend of 'White Flight' may not be as prominent today as it was in the 1950s, there still has been an avoidance of racially or ethnically diverse neighbourhoods among many White Americans in their residential relocation decisions. ${ }^{23}$ Research demonstrates that these migration decisions are based on the 'race-based neighbourhood stereotyping hypothesis', which asserts that the avoidance of neighbourhoods with communities of colour is due to perceptions of poverty, crime, disorder and ineffective schools. ${ }^{23}$ While these assertions are often cloaked in prejudicial inaccuracies, historically, people of colour have lived in economically disinvested, disadvantaged and impoverished areas. Unlike previous generations, however, the migration behaviours for generation Y or millennials may now be steeped in both a neighbourhood ethnoracial composition preference as well as an inclination to live in urban centres. A recent study found that this generation has been the driving force of urban resurgence within the past two decades due to their desire to live in central urban neighbourhoods. ${ }^{25}$ Just as 'urban renewal' resulted in the gentrification of older metropolitan neighbourhoods and displacement of residents, 'urban resurgence' has operated in the same manner. ${ }^{26}$ The places designated for urban renewal or urban resurgence, which are most often neighbourhoods with large communities of colour consisting of lowincome or middle-income residents, have been shown to experience a disproportionate increase in the number of white, young, well-educated and middle-income or highincome professionals. ${ }^{27-29}$ Likewise, neighbourhood and equity advocates have expressed concern that new TOD projects will lure wealthier and less diverse residents, which will lead to the displacement of existing populations, a phenomenon known as transit-induced gentrification (TIG). ${ }^{30}$ TIG, a TOD socioeconomic by-product, is defined as a phenomenon, whereby the provision of transit service, particularly LRT, and associated area of development, change in the direction of neighbourhood 'upscaling'. 31

The role of LRT investments in triggering gentrification and displacement of low-income households has been examined in several cities throughout the USA, such as Portland, OR and Denver, CO. ${ }^{32} 33$ For instance, the median household income increased by $10 \%$ in Denver, CO neighbourhoods near LRT stations and from 1990 to 2000 the housing values increased approximately $25 \%$ for those located within a mile from a LRT station. ${ }^{32}$ During this same time period of 1990-2000, the negative impacts of TOD, primarily with the introduction of LRT stations, in 42 neighbourhoods within 12 metropolitan areas that were first served by rail were observed through analysis. ${ }^{34}$ While there was no fundamental change in neighbourhood racial composition, rapid rises in rent 
and owner-occupied units were found, which resulted in more expensive housing stock, wealthier residents and increased vehicular ownership. ${ }^{34}$ With rising property values and loss of affordable housing, displacement, social loss (eg, disruption of neighbourhood social networks) and segregation have been documented as unfavourable TIG externalities, particularly in transit station neighbourhoods, which can impact current residents of the TOD. ${ }^{13} 3132$ 35-41 Even when positive neighbourhood features, namely, increased transit accessibility, are considered, many White Americans still prefer living among fewer persons of colour and when they do relocate to these neighbourhoods subtle mechanisms (eg, park renaming; cultural displacement) that encourage pre-existing residents of colour to move may ensue. ${ }^{234243}$ As such, social polarisation, or rather the splintering of a group into distinct sub-groups that are positioned on different ends of a spectrum (eg, rich vs poor), can emerge as a by-product of real-estate fluctuations and displacement. ${ }^{35}$

\section{Consequences of perceived TIG}

\section{Physical health consequences}

In many low-income areas and communities of colour, new transit investments are met with mixed reactions among current versus new residents or among residents who stay versus those who leave. In addition to the aforementioned negative impacts, TIG can engender health consequences when built, and social environments are rapidly transformed (figure 1). ${ }^{30}$ Studies have found that populations displaced by gentrification, as compared with those who remained, typically have a shorter life expectancy, higher cancer rates, more birth defects, greater infant mortality and higher incidence of asthma, diabetes and cardiovascular disease (CVD) ${ }^{36}{ }^{44-54}$ In one study, hypertension, one of the strongest risk factors for CVD, was inversely associated with neighbourhood affluence/ gentrification (OR 0.7 ; 95\% CI 0.6 to 0.9 ).${ }^{53} 55$ However, in another study, the risk of displacement was positively associated with hypertension ( $\mathrm{PR}=1.25 ; 95 \%$ CI: 1.08 to 1.46) and hypercholesterolemia, another risk factor for CVD, (PR=1.12; $95 \%$ CI: 1.01 to 1.24) among a population

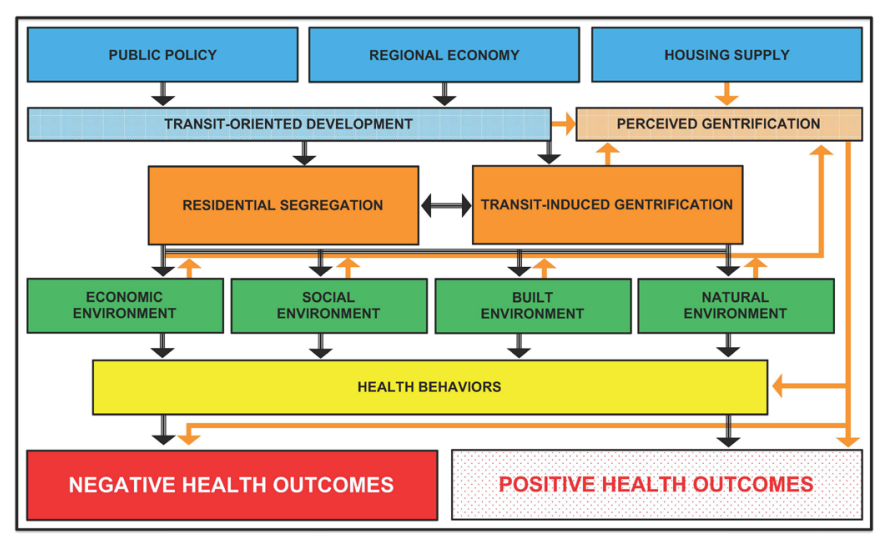

Figure 1 Perceived Gentrification and Health Outcome Model. of Hispanic renters in Chicago, IL; Miami, FL; New York City, NY and San Diego, CA. ${ }^{56}$ It was also found that the perception of neighbourhood problems and changes were strongly associated with adverse health behaviours, such as increased smoking, as well as hypertension in another cross-sectional study. ${ }^{57}$ These findings on displacement risk and neighbourhood perception shed light on the potential significance of perceived TIG, the perception of adverse neighbourhood changes among residents, and its impact on the health behaviours and health of current residents regardless of whether they stay or leave their neighbourhood. Changing variables, such as proximity to transit stops, housing type, education levels, population density, as well as cultural phenomena, can all be indicators of TIG progress. To further recognise the latter, cultural displacement, another aspect of gentrification that is often subtle and underappreciated, refers to classbased and race-based changes in amenity types, such as local establishments. Chain stores and restaurants often instigate a loss of cultural identity and sense of the place in neighbourhoods populated predominantly by people of colour. In Portland, OR, long-term African American residents experienced a profound change and alienation from new retail spaces on a gentrifying commercial main street. ${ }^{58}$ Unlike other social and economic processes, TIG often takes on specific dimensions locally or regionally, and therefore a universal measurement of TIG is highly improbable. ${ }^{59}$ Perceived TIG, such as through the observation of increasingly more affluent residents moving into the neighbourhood or through the presence of more police surveillance, can impart negative health outcomes primarily due to the unknown of 'if' and 'when' 'it' (eg, rent increase leading to a forced eviction/move) will happen.

\section{Mental health consequences}

Mental health outcomes, including an increased risk of psychological stress levels, anxiety and depression, have also been demonstrated among displaced populations. ${ }^{36446}$ The mental health impact related to social loss or the disruption of long-time residential ties and the sense of community diminishment could deteriorate a neighbourhood's resilience by weakening social networks. ${ }^{416061}$ Fear of displacement can heighten anxiety and result in increased mortality. ${ }^{46}{ }^{62}$ High residential turnover and disruptive impacts of resettlement have been found to be negatively related to lower selfrated health due to the loss of gathering spaces and institutions. Also, displaced residents have reported higher levels of anxiety due to changes in neighbourhood character, feeling unwelcomed and social isolation, all likely due to a loss of community. ${ }^{29}{ }^{63-65}$ Specifically, sense of community, a social psychology concept, is defined as a sense of belonging both on a geographical (eg, neighbourhoods) and a relational (eg, human relationships) scale. ${ }^{667}$ This concept, which leads residents to perceive and associate a strong identity with a particular setting, has been found to be an integral contributor to one's 
neighbourhood commitment, involvement and satisfaction. ${ }^{66}{ }^{68}$ Leveraging findings from psychology of place research, it can be theorised that when the four basic sense of community elements ((1) membership, (2) influence, (3) integration and needs fulfilment and (4) shared emotional connection) are threatened by displacement, anxiety and depression may ensue. ${ }^{406}$ For example, in a cross-sectional study examining the impact of residential displacement on mental health within gentrifying and non-gentrifying neighbourhoods from 2010 to 2014, displaced residents were more likely to be diagnosed with mental health-related conditions ( $37 \%$ vs $18 \%$ ) compared with residents who were not displaced. ${ }^{46}$ Another study showed that the stress of displacement among incumbent residents resulted in poor mental health, including anxiety and depression for $84 \%$ of men and $91 \%$ of women in a gentrified neighbourhood. ${ }^{69}$ Likewise, a repeated cross-sectional study determined that worsening neighbourhood perceptions were associated with small increases in depression. ${ }^{70}$ Again, perceptions were found to impart a negative health outcome. Yet, given all the research, it still is not well known if these mental health outcomes, or even increased CVD risk, are more likely to occur among current residents with poor or good health.

\section{Social determinants of health consequences}

The relationship between TIG perception and social determinants of health $(\mathrm{SDOH})$, or rather, factors that contribute to health, including the conditions of birth, growth, living, learning, working, playing and ageing, have been less understood. ${ }^{71}$ Research has shown that the availability of affordable housing and increase of walkable streets, as well as a reduction in crime, are $\mathrm{SDOH}$ related to gentrification and, more specifically, TIG. ${ }^{446}$ Although the presence of walkable streets during the construction period of TOD may be limited, the use of LRT after construction has been found to be associated with an increased likelihood of walking. ${ }^{72} \mathrm{~A}$ cross-sectional analyses reported that both men and women who reported a positive neighbourhood change inconvenience were twice as likely to increase their walking afterwards. ${ }^{73} \mathrm{In}$ regards to rates of crime and gentrification, this relationship has yielded inconclusive findings over the past several decades. A time-series analysis of crime rates between 1970 and 1984 in 14 gentrified neighbourhoods throughout Boston, MA; New York, NY; San Francisco, CA; Seattle, WA and Washington, DC indicated some eventual reduction in personal crime rates, but that there was no significant effect on property crime rates. ${ }^{74}$ Despite the crime type, the direct relationship between fear or perception of neighbourhood crime and community composition change have affirmed the characteristics of gentrification. ${ }^{75}$ Furthermore, when areas have gentrified and changed economically, police surveillance has increased and 'created conditions' for more 'behaviour misconduct' or behaviours that were previously considered normal, but that are now viewed as miscreant or suspicious among the newcomers. ${ }^{77}$ Although the relationship with TIG perception and SDOH may have varying directions of association, it is hypothesised that perceived TIG among current residents will be significantly related to walkability changes and to changes in crime within the neighbourhoods.

\section{Gauging effects of neighbourhood trends and sickness The GENTS study}

While some health outcome and SDOH changes have been found to be associated with gentrification and specifically displacement, there is a paucity of data examining the health impacts related to TIG perception. Furthermore, prior research used existing data and examined health outcome relationships retrospectively. The GENTS Study (Gauging Effects of Neighborhood Trends and Sickness: Examining the Perceptions of Transit-Induced Gentrification in Prince George's County) will address these limitations by using a longitudinal research framework at the neighbourhood level in order to examine health impacts related to TIG perception. Grounded in the previously discussed research and adapted from a study examining gentrification in the San Francisco, CA area, the GENTS Study conceptual model of perceived gentrification and health theorises that TOD, such as a new light rail line, can lead to both TIG and perceived TIG (figure 1) ${ }^{78}$ Instigated by any actual or perceived changes in the economic (eg, increased taxes), social (eg, perceived crime increase), built (eg, new sidewalks) or natural (eg, new parks) environments, as a result of the TOD, perceived TIG, by way of TIG or not, may be capable of influencing positive (eg, walking) or negative (eg, smoking) health behaviours. Ultimately, these health behaviours can bring about positive or negative health outcomes (figure 1orange arrows). Furthermore, it is theorised that perceive TIG can directly impact health outcomes. For example, if an individual observes an inflation of new neighbours, s/ he may perceive a social environment change, which may bring about a level of anxiety (negative health outcome) or initiate smoking (health behaviour), which may result in hypertension (negative health outcome). Conversely, if an individual's neighbourhood has undergone construction for new sidewalks leading to the TOD, s/he may begin walking (health behaviour), which may reduce hypertension (positive health outcome).

Leveraging an expansion of the Washington DC Metropolitan Area Transit Authority System as a natural experiment, the GENTS Study will add novel and unexplored evidence on the neighbourhood, health and TIG effects of a TOD within Prince George's (PG) County, Maryland during the construction period and before operation of the purple line (PL) LRT. In Spring 2022, the PL, a 16.2 mile LRT line, will begin operation in PG County, a suburban area of Washington, DC, comprised of over $80 \%$ African American and Hispanic residents. ${ }^{79}$ The GENTS Study will take advantage of this natural experiment and evaluate PL LRT-related neighbourhood changes and associated health impacts of perceived TIG among PG County adults in a quasi-experimental case-comparison 
group design involving cases living close to the PL LRT versus controls living father from the PL LRT, but who are similar demographically and in the initial built environment with two points of data collection (eg, wave 1 and wave 2). Although 'case-comparison' contrasts to the 'case' and 'control' definitions in traditional epidemiology, here case-comparison is defined as a study which compares a group receiving a built environment change or intervention (eg, PL LRT) to a comparison group that is not directly receiving the built environment change because of proximity or distance. ${ }^{80}$ Overall, the research question presented with this GENTS Study is whether or not neighbourhood perceptions, in the form of perceived TIG, can have deleterious effects on anxiety and CVD risk despite the initial health status of the current residents.

\section{Quasi-experimental design}

Approximately 20 pre-post natural experiment studies of a built environment change exploring longitudinal impacts have been conducted in the USA. ${ }^{81-83}$ Among these, only a few studies examined the impact of a new LRT, and the participant samples of all but one study consisted of over $70 \%$ white and non-Hispanic adults. ${ }^{728-87}$ The one study was composed of $45 \%$ African Americans, but there were over $90 \%$ non-Hispanic adults. ${ }^{88}$ Since it has been established that impoverished neighbourhoods and communities of colour often bear the brunt of unintended TOD impacts, there is an urgent need to establish the effects of a built environment modification and specifically a major transportation infrastructure change on perceived TIG and associated health outcome and SDOH changes among this population. Natural experiment studies are more generally susceptible to bias due to their quasiexperimental design, however, the GENTS Study presents a unique opportunity to examine unintended TOD impacts before the operation of a new LRT and among a predominate community of colour. When these natural experiments are designed appropriately, it is achievable to preserve and maintain the level of internal and external validity. Pre-existing neighbourhood preference, choice and residence and the lack of randomisation for the intervention (PL LRT) could pose some degree of individual-level bias via confounding (internal validity). Yet, the amount of bias associated with confounding will be minimised by using a quasi-experimental interrupted time series with comparison group design (figure 2). While the initial and unique focus of the GENTS Study occurs before the 'interruption' or PL LRT intervention through the collection of case and comparison group

\begin{tabular}{|c|c|c|c|c|c|}
\hline \multicolumn{6}{|c|}{ GENTS STUDY } \\
\hline STUdY GROUPS & \begin{tabular}{|c|} 
T.2 \\
WAVE 1 \\
DATA COLLECTION \\
\end{tabular} & \begin{tabular}{|c|} 
T-1 \\
WAVE 2 \\
DATA COLLECTION \\
\end{tabular} & TREATMENT & \begin{tabular}{|c|} 
Wa1 \\
WAVE 3 \\
DATA COLLECTION \\
\end{tabular} & $\begin{array}{c}\text { T+2 } \\
\text { WAVE 4 } \\
\text { DATA COLLECTION }\end{array}$ \\
\hline CASE PARTICIPANTS & \begin{tabular}{|c|} 
AUGUST 2020 \\
TO \\
JULY 2021 \\
\end{tabular} & \begin{tabular}{|c|} 
AUGUST 2021 \\
TO \\
JULY 2022 \\
\end{tabular} & \begin{tabular}{|c|} 
PURPLE LINE \\
LIGHT RAIL TRANSIT \\
$<1$-MILE NETWORK \\
\end{tabular} & To Be Determined & TO BE DETERMINED \\
\hline COMPARISON PARTICIPANTS & $\begin{array}{c}\text { AUGUST } 2020 \\
\text { TO } \\
\text { JuLr } 2021 \\
\end{array}$ & $\begin{array}{c}\text { AUGUST } 2021 \\
\text { TO } \\
\text { JULY } 2022 \\
\end{array}$ & \begin{tabular}{c|} 
PURPLE LINE \\
LIGHT RAAL TRANSIT \\
$>1$-MILE NETWORK \\
\end{tabular} & To Be Determined & To Be DetermINED \\
\hline
\end{tabular}

Figure 2 Gauging Effects of Neighbourhood Trends and Sickness (GENTS) Study Design. data at two time points, this study will ultimately collect data after the interruption. Also matching intervention and control groups can be challenging in a natural experiment, but for this study, the comparison and control participants will be as similar as possible through the use of analytical methods at baseline (see Data Analysis).

\section{GENTS study aim I: compare perceived TIG with health outcome} changes

For this first aim, the GENTS Study will assess the association of perceived TIG with measured health outcome changes ((1) anxiety, (2) CVD risk) among PG County adults while also comparing these associations between case and comparison participants. At two pre-PL LRT data collection points, perceived TIG and both health outcomes measures will be examined. Perceived TIG, anxiety and CVD risk will be assessed in order to examine changes in perceived TIG with changes in health outcomes. The objective of this aim is to determine whether the impact of perceived TIG (eg, negative neighbourhood changes) will have an impact on health outcomes and if these impacts vary between case and comparison residents.

\section{GENTS study aim II: compare perceived TIG with SDOH changes}

The GENTS Study will assess the association of perceived TIG with SDOH changes, including measured ((1) walkability, (2) crime) and perceived ((3) walkability; (4) crime) and compare these associations in case and comparison participants at two pre-PL LRT data collection points. This aim is not suggesting that perceived TIG will lead to changes in walkability or crime. However, if there are changes in measured or perceived walkability or crime, which are often byproducts of TIG, then it would be expected that changes in perceived TIG would be observed.

\section{METHODS AND ANALYSIS}

\section{Purple line light rail line}

Under the Maryland Transit Administration (MTA) leadership, the 16.2 mile PL LRT is anticipated to open for operation in late 2022. ${ }^{89}$ However, it was announced late 2019, that the line would open in two phases. The first segment carrying passengers in PG County will open in late 2022 and the remainder of the line will open in 2023. The PL LRT, which began construction in 2016, will extend east from Bethesda (Montgomery County) to New Carrolton (PG County) and connect to existing Red, Green, and Orange Metrorail lines of the Metro System (figure 3) ${ }^{90}$ Within PG County, there will be a total of 11 stops/stations, including five stops that will be located directly on or adjacent to the University of Maryland (UMD) campus. PL LRT will operate mainly in dedicated lanes and will also connect to MARC, Amtrak and local bus services. It will consist of quietly operated modern streetcars powered by overhead wires with neighbourhood stations convenient for pedestrians. ${ }^{89}$ The PG 


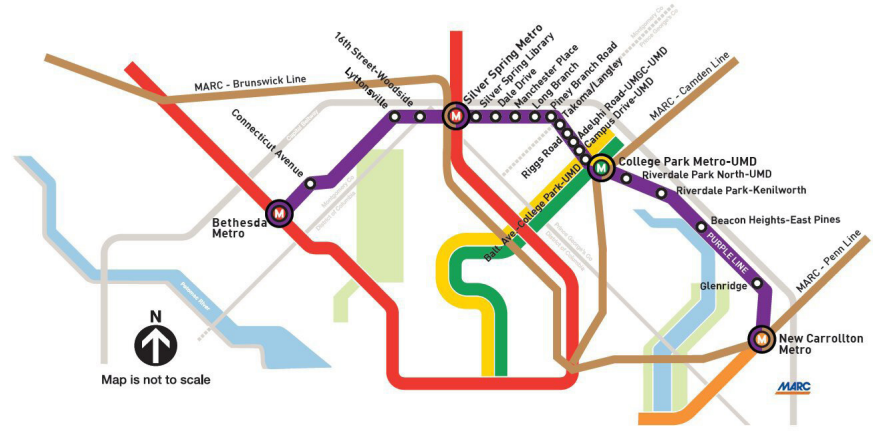

Figure 3 Maryland Transit Administration Purple Line Map. Source: Maryland Transit Administration.

County portion of the PL LRT will be bookended by the Takoma Langley Transit Center and New Carrolton Metrorail stop. The entire PL LRT will connect PG County with Montgomery County, one of the most affluent areas in the USA, and an attraction for employment and entertainment. Areas around the new PL LRT stations/stops in PG County will experience infrastructure changes, new housing, retail development and the construction of a bike path through the UMD Campus. ${ }^{89}$

\section{Study design and setting}

As a supplement to the existing Purple Line Impacts on Neighborhood, Health and Transit (PLIGHT) Study, which is focusing on changes in physical activity, active transportation, obesity and obesity related-CVD, the GENTS Study will examine the TIG perception and its relationship to health outcome and SDOH changes in the pre-PL LRT period. ${ }^{91}$ The GENTS Study will use a quasi-experimental case-comparison design to evaluate PL LRT-related neighbourhood changes and associated health impacts of perceived TIG among PG County adults by collecting data at two points of time. The intervention site will consist of case residents within a 1 mile network buffer around the PL LRT stations/stops in PG County. The 1 mile network buffer was chosen because it includes a comfortable walking distance and supports research indicating that individuals are willing to walk to reach transit beyond the frequently cited 0.25-to-0.50-mile demarcation. ${ }^{92-99}$ Comparison residents will consist of individuals living greater than 1 mile but less than 5 miles from the PL LTR stations/stops (figure 4).

\section{Patient and public involvement}

Participants or the public were not involved in the design, conduct, reporting or dissemination plans of this research.

\section{Participant recruitment and study population}

A rolling recruitment and enrolment strategy will be used with three questionnaire deployment pathways over a 12 month wave (Wave 1-August 2020 to July 2021) in order to achieve a baseline sample. Once achieved, the second data collection point will occur during a second 12 month wave (Wave 2-August 2021 to July 2022). Questionnaire deployment pathways ((A) Snowball Sampling;

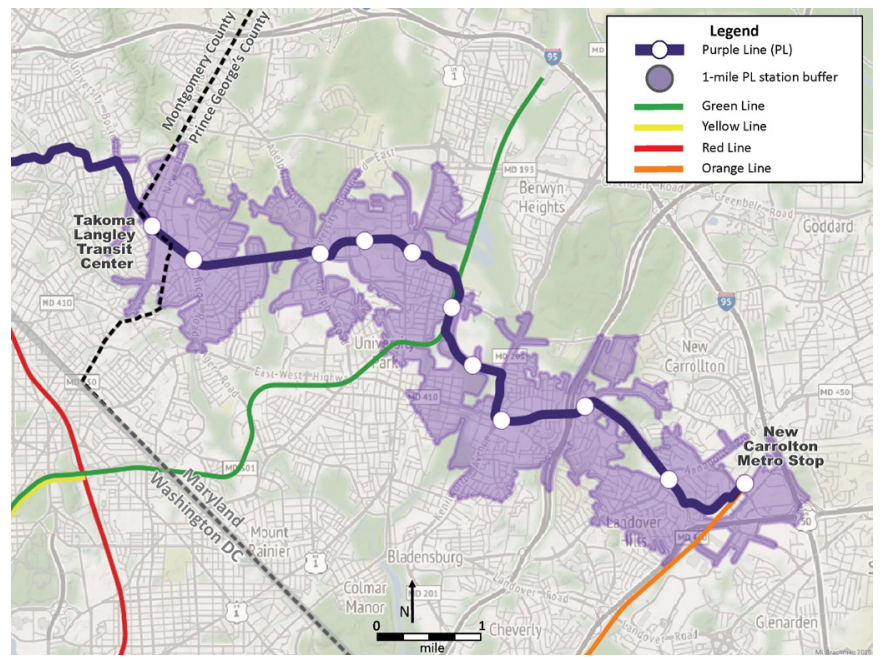

Figure 4 Gauging Effects of Neighbourhood Trends and Sickness Study Area.

(B) On-Site Sampling; (C) Email Blast Sampling) will cast the initial recruitment net from the PL LRT catchment area. Eligible participants must be an adult (18 years and older) and a PG County resident. Individuals will not be eligible to participate if they (a) have a physical impairment, disability or medical condition that prevents them from engaging in normal daily activities; or (b) are planning to relocate away from the study area and/or PG County within 36 months from the study baseline. Therefore, UMD students will be excluded. For each of the two waves of data collection, participants will be offered a $\$ 25$ USD gift card.

To determine the required number of participants, four assumptions for the sample size calculation were used: (1) the attrition from wave 1 to wave 2 data collection is $9 \%$; (2) equal sample sizes between case and comparison groups at baseline (wave 1); (3) power of 0.9 ; (4) correlation between multiple measurements within a participant is between 0.5 and 0.8 and (5) minimum detectable effect size of $0.3 \mathrm{SD}$ units of PL LRT use at the second data collection. Therefore, a total of 800 participants at baseline based on these assumptions is required. Each participant's home address will determine if $\mathrm{s} /$ he is a case or comparison participant. During recruitment, the demographics of the participant sample will be continually evaluated to maintain its representation. If required, additional targeted recruitment will be initiated to ensure demographic consistency and adequate case and comparison representation. Also, as data are collected, researcher-to-participant contact will be maintained with birthday messages, reminders, study newsletters and update emails of the GENTS Study.

\section{GENTS study questionnaire}

Questionnaire deployment

Qualtrics.com will host the online GENTS Study questionnaire in English and Spanish (see online supplemental material 1). Forward and backward translation validation will occur for the Spanish language questionnaire. 
Three questionnaire deployment pathways will be used on a rolling basis. The first deployment pathway will occur through snowball sampling with community partnerships, referrals from participants, and mining community email databases (eg, PG County Department of Parks and Recreation). Community outreach efforts, such as distributing informational quarter cards to recreational community centres and publishing announcements in local circulars with the GENTS Study website and questionnaire link, will be employed to recruit a representative sample and target underrepresented populations. The second deployment pathway will occur through on-site sampling. GENTS Study researchers will attend community events (eg, farmer's markets), equipped with iPads for participants to begin questionnaires in person, and show how individuals can complete the questionnaire on their smartphones since Qualtric.com provides a very user-friendly smartphone platform. According to Pew Research Center, nearly all Americans (96\%) now own a cellphone. ${ }^{100}$ For individuals who are unable to complete the questionnaire on-site, and in light of the COVID-19 pandemic and social distancing guidelines (see the Discussion section), GENTS Study informational quarter cards will be distributed with the website and questionnaire link. Finally, the third deployment pathway will occur through email blast sampling with the Alesco Data Group, a direct marketing services company that draws from a consumer database of over 149 million addresses in the USA. ${ }^{101}$ This third pathway will begin with the purchase of 10000 PG County household email addresses matched with resident name and postal address within the GENTS Study catchment area for the recruitment of case and control participants. Invitational questionnaire links will be emailed to all 10000 addresses. While recruitment will occur through three questionnaire deployment pathways as previously described, for the third deployment pathway, we anticipate an $5 \%$ response rate, resulting in a sample of approximately 500 (250 cases; 250 comparisons), based on prior research within this regional population. ${ }^{102} 103$ Predictions about the sample size generated from the other pathways cannot be estimated at this time, however, as mentioned previously a total of 800 participants at baseline is required.

\section{Questionnaire measurement}

TIG is a phenomenon that may occur rapidly at times, and the GENTS Study will examine TIG perception during the pre-PL LRT period. It is essential to capture information on individual perceptions and examine how or why those perceptions may or may not change. Perceived TIG will be assessed through the questionnaire. Findings from previous TIG research identifying gentrification indicators, as well as the qualitative data collected for the PLIGHT Study, will inform the development of these questionnaire items. ${ }^{91}$ Specifically, the Neighborhood Change and Gentrification Scale (NCGS), a 10-item scale using a five-point Likert response rating of agreement, created and developed by researchers in the social service field will be used to assess perceived TIG. ${ }^{104}$ Four of the NCGS items were developed based on prior research using census-based measures of neighbourhood gentrification (eg, 'I have seen an increased influx of affluent and nonminority residents moving into the neighbourhood.'). The other six items were drawn from qualitative and quantitative self-reported research experiences on gentrification (eg, 'I have feared being 'pushed out' of my neighbourhood.' In addition, demographic information (eg, race, ethnicity, age) and other relevant information, such as housing tenure, homeownership, transit, commuting patterns and physical activity behaviours will also be collected as these data may influence TIG perception (see online supplemental material 1).

Sense of community, as well as anxiety, will be assessed using the Sense of Community Index Version Two (SCI-2) and Kessler Psychological Distress Scale (K10), respectively. SCI-2, an instrument bridging the public health, environmental psychology, engineering, and design fields, demonstrates high reliability with strong validity. ${ }^{105} 106$ Furthermore, K10 is a reliable and valid 10-item questionnaire providing a global measure of distress based on questions about anxiety and depressive symptoms experienced in the most recent month. ${ }^{107}$

Even though CVD generally includes heart conditions involving diseased vessels, structural problems and blood clots, capturing each and every type of stage of CVD is not only impractical, but it also would not necessarily identify early disease stage individuals. Therefore, changes in hypertension, one of the strongest risk factors for almost all different types of CVD, will be used as the primary metric for CVD risk. ${ }^{55}$ Questionnaire items assessing hypertension and CVD prevalence will be adopted from the National Health and Nutrition Examination Survey. Additionally, questions from the Framingham Heart Study will be used to ask about key traditional CVD risk factors.

Changes in actual walkability will be examined in two ways. First, components of walkability, including street connectivity, infrastructure for walking, neighbourhood aesthetics, traffic and crime safety, will be assessed with the Neighborhood Environment Walkability Survey-Abbreviated (NEWS-A). ${ }^{108}$ Second, WalkScore, a large-scale, publicly available index that assigns a numerical walkability score to any address in the USA, will also assess changes in walkability through PG County neighbourhoods. ${ }^{109}$ Perceived walkability will be assessed through items previously used in validated instruments. ${ }^{110}$

Finally, changes in personal and property crime rates will be examined. Data on assaults, burglaries, homicides, robberies, sex offences, stolen vehicles, thefts and vandalism will be obtained from the PG County Police Department data. These data will be geographically mapped so that spatial and temporal changes in crime can be assessed. With PG County Police Department being the fourth largest law enforcement agency in the State of Maryland and within a demographically and geographically diverse area, enforcement patterns will 
also be examined as these patterns can influence crime distribution throughout the county. Trends in offence type by age, race, ethnicity, gender and geography will be considered based on the availability of data. ${ }^{111}$ Finally, perceived crime will be assessed through questionnaire items previously used in validated instruments. ${ }^{110}$

\section{Data management and analyses}

Throughout the course of the GENTS Study, data will be downloaded from Qualtrics.com and managed on a secure and password protected UMD sever. All nonelectronic data will be stored in a locked file cabinet that is located in the swipe card and key accessed PHOEBE Lab of the Principal Investigator (Roberts). Visualisations and descriptive statistics will examine data distributions, identify category thresholds, outliers, and missing values, and audit data for any problems with the planned statistical methods. Variables may be transformed or analogous non-parametric tests used if statistical assumptions are severely violated. The population representativeness of the sample and comparability between case and comparison groups will be evaluated. As missing data problems arise, sensitivity analyses will evaluate statistical tests for robustness.

Between group analysis (eg, cases vs comparisons) will be performed to address sources of bias and strengthen the causal inferences from this natural experiment. To help adjust for any potential variation in the characteristics of the case versus comparison groups at baseline various analytical methods (eg, propensity score matching) will be used. Initially, t-tests among cases and comparisons and longitudinally will be conducted. Paired t-tests will be used to compare health outcome and SDOH changes within the two pre-PL LRT periods. Plus, latent growth curve (LGC) modelling will assess health outcome and SDOH changes. ${ }^{112}$ This technique can model linear and curvilinear relationships and incorporate other statistics to determine if the hypothesised models adequately fit the observed data. ${ }^{5112}$ LGC can be structured as a piecewise model, such that discrete periods of time can have markedly different slopes. ${ }^{113}$ LCG can accommodate latent or unobserved factors and can handle both timevariant (eg, neighbourhood perceptions) and invariant (eg, race/ethnicity) variables. ${ }^{114}$ There is no requirement that there be more than two measurements or that the measurement times be equally spaced. ${ }^{115}$ Also, individual times of observation are allowed to vary. Potential confounders will be identified and measured as well as contextual variable threats (eg, sociodemographic variables) to external validity (generalisability) and then adjusted for these modelling approaches.

For aim I, LGC modelling will first construct unconditional LGC measurement models, in which perceived TIG and psychological stress are each modelled only as a function of time. ${ }^{112} 116117$ If a linear model is not satisfactory, alternative curvilinear models can be specified and tested. Since this aim seeks to determine wave 1 versus wave 2 PL LRT effects, a piecewise growth model may also be specified. ${ }^{113}$ This approach may be appropriate if a sharp initial increase in perceived TIG and anxiety in the months closer to the PL LRT opening are observed. Second, if substantial individual variance around the mean growth curve is observed in the unconditional model, the growth factors (the latent slope(s) and intercept) will be regressed on exogenous explanatory variables in a conditional LGC model. ${ }^{116} 117$ For aim I, the primary explanatory variable is whether or not a participant resides in the PL LRT intervention (case vs comparison area). This takes the general form of $\eta_{i}=\bar{\Phi}+\gamma X_{i}+\beta_{i} T_{i}$ $+\varepsilon_{i}$, where $\eta_{i}$ is a $\mathrm{J} \times 1$ vector of latent growth factors, $\bar{\omega}$ is a J $\times 1$ vector of regression intercepts, $X_{i}$ is a $\mathrm{K} \times 1$ vector of covariate variables, $\gamma$ is a $\mathrm{J} \times \mathrm{K}$ matrix of regression coefficients, $T_{i}$ is the intervention indicator variable, $\beta_{i}$ is the coefficient for the treatment indicator variable and $\varepsilon_{i}$ is a $\mathrm{J} \times 1$ vector of residuals, which has a multivariate normal distribution accounting for the within-subject correlation. If the change over time in perceived TIG and anxiety is different in the case participants exposed to the new PL LRT line compared with the comparison participants not exposed, an understanding of this phenomenon can be achieved by regressing the growth factors on the PL LRT case versus comparison condition (located in the $\mathrm{x}$ vector). The $\mathrm{x}$ vector contains covariates, such as sex, race, age, and propensity scores. This modelling application will be repeated to model CVD risk, specifically hypertension. Furthermore, this modelling approach will be repeated for aim II in order to model the association of walkability and crime with perceived TIG while also comparing these associations between case and comparison participants.

\section{DISCUSSION}

This natural experiment is one of only a few to investigate the relationship between perceived TIG, health outcomes and $\mathrm{SDOH}$ in a predominant community of colour. The diversity of the PG County Study population is a unique feature of this research especially considering the fact that the African American proportion of similar studies performed in Philadelphia and California was only 22\% and 5.6\%, respectively. ${ }^{62} 118119$ The inclusion of these underrepresented populations is crucial to the validity of the study results, but more importantly adequate representation of the GENTS Study is essential to address the research questions and policy issues that are specifically tailored to PG County.

This research will add to the growing body of literature and urgency suggesting that plans to invest in transportation infrastructure can impact the health of the residents even before the infrastructure is in place. There has been very little research on whether different phases of LRT construction, independent of public investments and regulations, have any effect on the gentrification process and/or the health of residents. One approach to exam this issue is to observe and evaluate how residents and other community stakeholders respond to TOD 
plan announcements. As an example, one of the main questions posed by Knaap, Ding, and Hopkins was 'Do Plans Matter?'. It was found that plans do indeed matter when the plans for LRT investments increased the land value in proposed station areas. ${ }^{120}$ Most recently National Public Radio published an article entitled 'How To Limit Gentrification Along The Purple Line, According To Housing Advocates' where is was stated that 'Apartment dwellers in Langley Park, Maryland, are at risk of rent hikes as the Purple Line spurs development in the area'. ${ }^{121}$ A plan from the Purple Line Corridor Coalition, a group of nonprofit leaders, planners, developers and others convened by UMD's National Center for Smart Growth to advise local leaders and organisations, recommends actions to preserve affordable housing and reduce displacement along the path of the PL LRT, which is expected to transform economically distressed neighbourhoods. ${ }^{121}$ Since gentrification is a dynamic process, it is necessary to compare regional changes over time and space. The GENTS Study will identify changes over time in perceived TIG, health outcomes and SDOH among case and comparison residents before the completion and operation of the PL LRT, an under researched period of TOD. Furthermore, this research will be able to capture evidence as to the effectiveness of the Purple Line Corridor Coalition plan.

While strengths of this study lie in the diversity of the study population as well as the timing of the natural study, it is important to recognise possible challenges. It is expected that recruitment efforts may take a longer period of time considering that recruitment will occur within in a predominately African American and Hispanic population who may have a strong hesitancy and an overarching sense of distrust with research participation. ${ }^{122-124}$ Maryland has a large immigrant population (15.2\%) and over $27 \%$ are undocumented and are centred in PG County. ${ }^{125} 126$ As such, time is needed for community engagement in order to demonstrate trustworthiness and commitment. Additionally, retention efforts will need to be robust through consistent participant communication and community visibility of the GENTS Study. Furthermore, that launch of the GENTS Study is occurring during an exceptionally remarkable period of time. Since the early part of this year, the COVID-19 pandemic has significantly devastated communities worldwide. In order to adapt to the new challenges of social distancing and living through a disease outbreak, the questionnaire deployment pathways will physical human interaction (eg, on-site sampling) may need to be temporarily modified. Also, COVID-19 risk perception questions will be added to the questionnaire. These questions will examine COVID-19 risk perceptions in general and as related to public transit. While the online questionnaire will generally ask respondents about outcomes, perceptions, attitudes and behaviours within the past months (see online supplemental material 1), the COVID-19 risk perception of transmission, disease and death may have a sustaining impact for years to come. Moreover, the focus of the
GENTS Study is related to public transit and the forthcoming PL LRT. Public transit has been scrutinised as an optimal source and environment for COVID-19 transmission and as such ridership has dwindled in many cities. ${ }^{127}$ A recent study found that public transportation users perceived a greater COVID-19 risk exposure compared with personal vehicle users and those who walked. ${ }^{128}$ Despite these limitations and unexpected events, it is anticipated that the GENTS Study will contribute significantly to the research field and fill gaps in the literature on the health and well-being impacts of TIG. Moreover, findings from this research will be able to address research questions and policy issues that are specifically tailored to PG County while also providing more effective procedural solutions for other regions undergoing TOD and TIG risk.

\section{ETHICS AND DISSEMINATION}

\section{Ethics approval and consent to articipate}

The Institutional Review Board at The University of Maryland at College Park has approved this study protocol (see online supplemental material 2). Information about the GENTS Study will be provided at the beginning of the questionnaire. This information will be written at a reading level that is easily understood by all, indicating that participation is voluntary, that he/she is free to withdraw participation any time without penalty, a description of measures that will be taken to ensure privacy, and how the results will be used. Adult participants will be required to click a button to acknowledge that they have read the study information and then informed consent will be obtained on questionnaire completion. The informed consent form will be returned electronically with the questionnaire. Participants will be instructed to print or email a copy for their records.

\section{Author affiliations}

${ }^{1}$ Kinesiology, University of Maryland at College Park, College Park, Maryland, USA

${ }^{2}$ School of Architecture and Environmental Design, Iran University of Science and Technology, Tehran, Islamic Republic of Iran

${ }^{3}$ Geographical Sciences, University of Maryland at College Park, College Park, Maryland, USA

${ }^{4}$ Medical Education, Morehouse School of Medicine, Atlanta, Georgia, USA

Acknowledgements The authors would like to thank the Agents of Change Writing Group, Maryland Center for Health Equity and the Directors and Fellows of the JPB Environmental Health Fellowship.

Contributors JDR conceived and designed the GENT Study. JDR wrote and drafted the manuscript with SOT. EAS and RI edited components of the manuscript. VNG provided methodology expertise for the study design. MLB provided GIS expertise and created the GENT Study map. All authors have read and approved the manuscript.

Funding This research is being supported and funded by a JPB Environmental Health Fellowship (grant number 259798) operationalised through Harvard University T.H. Chan School of Public Health.

Map disclaimer The depiction of boundaries on this map does not imply the expression of any opinion whatsoever on the part of BMJ (or any member of its group) concerning the legal status of any country, territory, jurisdiction or area or of its authorities. This map is provided without any warranty of any kind, either express or implied. 
Competing interests None declared.

Patient and public involvement Patients and/or the public were not involved in the design, or conduct, or reporting, or dissemination plans of this research.

Patient consent for publication Not required.

Provenance and peer review Not commissioned; externally peer reviewed.

Open access This is an open access article distributed in accordance with the Creative Commons Attribution Non Commercial (CC BY-NC 4.0) license, which permits others to distribute, remix, adapt, build upon this work non-commercially, and license their derivative works on different terms, provided the original work is properly cited, appropriate credit is given, any changes made indicated, and the use is non-commercial. See: http://creativecommons.org/licenses/by-nc/4.0/.

\section{ORCID iD}

Jennifer D Roberts http://orcid.org/0000-0002-1850-4341

\section{REFERENCES}

1 Brulle RJ, Pellow DN. Environmental justice: human health and environmental inequalities. Annu Rev Public Health 2006;27:103-24.

2 Rodier C, Alemi F, Johnston RA. Exploring unintended environmental and social-equity consequences of transit oriented development: a research report from the National center for sustainable transportation. National center for sustainable transportation UC Davis Institute of transportation studies, 2015. https://ncst.ucdavis.edu/wp-content/uploads/2014/08/02-26-2016NCST-Rodier-Report-FINAL v2.pdf

3 Jacobson J, Forsyth A. Seven American TodS: good practices for urban design in Transit-Oriented development projects. $J$ Transp Land Use 2008;1:51-88.

4 Higgins C, Ferguson M, Kanaroglou P. Light rail and land use change: rail transit's role in reshaping and revitalizing cities. J Public Trans 2014;17:93-112.

5 Durand CP, Oluyomi AO, Gabriel KP, et al. The effect of light rail transit on physical activity: design and methods of the TravelRelated activity in neighborhoods study. Front Public Health 2016;4:103.

6 Neff J, Dickens M. Public transportation fact book appendix A: historical tables. American public transportation association, 2012. Available: http://www.apta.com/resources/statistics/Documents/ FactBook/2012-Fact-Book-Appendix-A.pdf [Accessed 23 Oct 2016].

7 Boorse JW, Tennyson EL, Schumann JW. This is light rail transit. Transportation research board, Washington, D.C, 2000. Available: https://www.apta.com/resources/reportsandpublications/ Documents/light_rail_bro.pdf [Accessed 9 Sep 2018].

8 Bauer T, Fuller P. An evaluation of light rail transit signal control options. Institute of transportation engineers annual meeting and exhibit, 2002. Available: https://pdfs.semanticscholar.org/76ef/c3b4 20c41d7f0243bf35359a008e8a065ac7.pdf [Accessed 9 Sep 2018].

9 American Public Transportation Association. Public transportation fact book - 2015, 2015. Available: http://www.apta.com/resources/ statistics/Documents/FactBook/2015-APTA-Fact-Book.pdf [Accessed 3 Nov 2016].

10 United States Census Bureau. Commuting in the United States 2009, 2011. Available: https://www.census.gov/prod/2011pubs/ acs-15.pdf [Accessed 21 Oct 2016]

11 Bopp M, Gayah VV, Campbell ME. Examining the link between public transit use and active commuting. Int $J$ Environ Res Public Health 2015;12:4256-74.

12 Anderson M. Who relies on public transit in the U.S. Pew research center., 2016. Available: https://www.pewresearch.org/fact-tank/ 2016/04/07/who-relies-on-public-transit-in-the-u-s/ [Accessed 1 Jul 2020].

13 Dong $\mathrm{H}$. Rail-transit-induced gentrification and the affordability paradox of Tod. J Transp Geogr 2017;63:1-10.

14 Ahlfeldt GM, Wendland N. Looming stations: valuing transport innovations in historical context. Econ Lett 2009;105:97-9

15 Duncan M. The impact of transit-oriented development on housing prices in San Diego, CA. Urban Stud 2011;48:101-27.

16 Gibbons S, Machin S. Valuing rail access using transport innovations. J Urban Econ 2005;57:148-69.

17 Victoria Transport Policy Institute. Evaluating public transportation health benefits, 2010. Available: https://www.apta.com/resources/ reportsandpublications/Documents/APTA_Health_Benefits_Litman. pdf [Accessed 17 Feb 2019].
18 Mohammad SI, Graham DJ, Melo PC, et al. A meta-analysis of the impact of rail projects on land and property values. Transport Res Part A: Pol Pract 2013;50:158-70.

19 Golub A, Guhathakurta S, Sollapuram B. Spatial and temporal capitalization effects of light rail in Phoenix: from conception, planning, and construction to operation. J Plan Edu Res 2012;32:415-29.

20 Bullard RD. All transit is not created equal. race, poverty and the environment, 2006. Available: http://www.reimaginerpe.org/files/2. Robert.D.Bullard.pdf [Accessed 24 Feb 2017].

21 Victoria Transport Policy Institute. Evaluating active transport benefits: guide to Valuing walking and cycling improvements and Encouragement programs, 2017. Available: http://www.vtpi.org/ nmt-tdm.pdf [Accessed 8 Dec 2017].

22 Hamidi S, Ewing R, Renne J. How affordable is HuD affordable housing? Hous Policy Debate 2016;26:437-55.

23 Pais JF, South S, Crowder K. White flight revisited: a multiethnic perspective on neighborhood out-migration. Popul Res Policy Rev 2009;28:321-46.

24 Ellen IG. Sharing America's neighborhoods: the prospects for stable racial integration. Cambridge, MA: Harvard University Press, 2000.

25 Lee Y, Lee B, Shubho MTH. Urban revival by millennials? Intraurban net migration patterns of young adults, 1980-2010. J Reg Sci 2019;59:538-66.

26 Mehdipanah R, Marra G, Melis G, et al. Urban renewal, gentrification and health equity: a realist perspective. Eur J Public Health 2018;28:243-8.

27 Landis JD. Tracking and explaining neighborhood socioeconomic change in U.S. metropolitan areas between 1990 and 2010. Hous Policy Debate 2016;26:2-52.

28 Freeman L. Displacement or succession: residential mobility in Gentrifying neighborhoods. Urban Aff. Rev 2005;40:463-91.

29 Hwang J. The social construction of a Gentrifying neighborhood: Reifying and redefining identify and boundaries in inequality. Urban Aff. Rev 2016;52:98-128.

30 Dawkins C, Moeckel R. Transit-induced gentrification: who will stay, and who will go? Hous Policy Debate 2016;26:801-18.

31 Zuk M, Chapple K. Urban displacement project. University of California Berkeley, University of California Los Angeles, 2015. Available: http://www.urbandisplacement.org/map/la [Accessed 24 Feb 2017].

32 Bardaka E, Delgado MS, Florax RJGM. Causal identification of transit-induced gentrification and spatial spillover effects: the case of the Denver light rail. J Transp Geogr 2018;71:15-31.

33 Knaap GJ, Ding C, Hopkins LD. Do plans matter?: the effects of light rail plans on land values in station areas. J Plan Educ Res 2011:21:32-9.

34 Pollack S, Bluestone B, Billingham C. Maintaining diversity in America's transit-rich neighborhoods: tools for equitable neighborhood change. A report prepared by the Dukakis center for urban and regional policy at Northeastern University, 2010. Available: http://www.pschousing.org/files/Northeastern\%20-\% 20TOD\%20equity\%20exec\%20summary.pdf [Accessed 8 Mar 2019].

35 Walks RA, Maaranen R. Gentrification, social mix, and social polarization: testing the linkages in large Canadian cities. Urban Geogr 2008;29:293-326.

36 Desmond M, Kimbro RT. Eviction's fallout: housing, hardship, and health. Social forces, 2015. Available: https://scholar.harvard.edu/ files/mdesmond/files/desmondkimbro.evictions.fallout.sf2015 2.pdf [Accessed 7 Mar 2019].

37 Shappard S. Why is gentrification a problem? centre for creative community development C3d. Williams College, 2012. Available: https://web.williams.edu/Economics/ArtsEcon/library/pdfs/Whyl sGentrificationAProbREFORM.pdf [Accessed 7 Mar 2019].

38 Chava J, Newman P, Tiwari R. Gentrification of station areas and its impact on transit ridership. Case Stud Transp Policy 2018:6:1-10.

39 Nilsson I, Delmelle E. Transit investments and neighborhood change: on the likelihood of change. J Transp Geogr 2018;66:167-79.

40 Fullilove MT. Psychiatric implications of displacement: contributions from the psychology of place. Am J Psychiatry 1996;153:1516-23.

41 Fullilove MT. Root shock: how tearing up city neighborhoods hurts America, and what we can do about it. New York: One World/ Ballantine, 2004.

42 Charles CZ. Won't you be my neighbor? Race, class, and residence in Los Angeles. NEw York, NY: Russell Sage Foundation, 2006.

43 Farley R, Steeh C, Krysan M, et al. Stereotypes and segregation: neighborhoods in the Detroit area. Am J Sociol 1994;100:750-80. 
44 US Centers for Disease Control and Prevention. Health effects of gentrification, 2013. Available: https://www.cdc.gov/healthyplaces/ healthtopics/gentrification.htm [Accessed 24 Feb 2017].

45 Casa De Maryland Inc. CASA de Maryland Langley Park promise neighborhood, 2012. Available: https://www2.ed.gov/programs/ promiseneighborhoods/2012/app-casa.pdf [Accessed 25 Feb 2017].

46 Lim S, Chan PY, Walters S, et al. Impact of residential displacement on healthcare access and mental health among original residents of gentrifying neighborhoods in New York City. PLoS One 2017;12:e0190139.

47 Wilder V, Mirto A-L, Makoba E, et al. The health impact of Gentrification. J Gen Emer Med 2017;2:1-4.

48 Xue Y, Leventhal T, Brooks-Gunn J, et al. Neighborhood residence and mental health problems of 5- to 11-year-olds. Arch Gen Psychiatry 2005;62:554-63.

49 Diez-Roux AV, Nieto FJ, Muntaner C, et al. Neighborhood environments and coronary heart disease: a multilevel analysis. Am J Epidemiol 1997;146:48-63.

50 Borrell LN, Diez Roux AV, Rose K, et al. Neighbourhood characteristics and mortality in the Atherosclerosis risk in Communities study. Int J Epidemiol 2004;33:398-407.

51 Huynh M, Maroko AR. Gentrification and preterm birth in New York City, 2008-2010. J Urban Health 2014;91:211-20.

52 Desmond M, Shollenberger T. Forced displacement from rental housing: prevalence and neighborhood consequences. Demography 2015;52:1751-72.

53 Morenoff JD, House JS, Hansen BB, et al. Understanding socia disparities in hypertension prevalence, awareness, treatment, and control: the role of neighborhood context. Soc Sci Med 2007;65:1853-66.

54 Kershaw KN, Osypuk TL, Do DP, et al. Neighborhood-level racial/ethnic residential segregation and incident cardiovascular disease: the multi-ethnic study of atherosclerosis. Circulation 2015;131:141-8.

55 Kjeldsen SE. Hypertension and cardiovascular risk: general aspects. Pharmacol Res 2018;129:95-9.

56 Chambers EC, Hanna DB, Hua S, et al. Relationship between area mortgage foreclosures, homeownership, and cardiovascular disease risk factors: the Hispanic community health Study/Study of Latinos. BMC Public Health 2019:19:77.

57 Gary TL, Safford MM, Gerzoff RB, et al. Perception of neighborhood problems, health behaviors, and diabetes outcomes among adults with diabetes in managed care: the translating research into action for diabetes (triad) study. Diabetes Care 2008;31:273-8.

58 Monroe Sullivan D, Shaw SC, Sullivan DM. Retail gentrification and race: the case of Alberta street in Portland, Oregon. Urban Aff Rev Thousand Oaks Calif 2011;47:413-32.

59 Murphy D. Crime stats or coffee shops? How to spot the world's most gentrified cities The Guardian, 2016. Available: https://www. theguardian.com/cities/2016/sep/30/worlds-most-gentrified-citiescrime-stats-coffee-shops [Accessed 8 Sep 2019].

60 International Making Cities Livable LLC. The other side of gentrification: health effects of displacement, 2017. Available: http:// www.livablecities.org/blog/other-side-gentrification-health-effectsdisplacement [Accessed 24 Feb 2017].

61 Lawrence DD. Community development: can communities effectively fight displacement caused by gentrification? J Afford Housing Comm Develop Law 2001;11:357-73.

62 Gibbons J, Barton M, Brault E. Evaluating gentrification's relation to neighborhood and city health. PLoS One 2018;13:e0207432.

63 Newman K, Wyly EK. The right to stay put, revisited: gentrification and resistance to displacement in New York City. Urban Stud 2006;43:23-57

64 Freeman L. There goes the hood: views of gentrification from the ground up. Philadelphia, PA: Temple University Press, 2006.

65 Boyd M. The downside of racial uplift: meaning of gentrification in an African American neighborhood. City \& Society 2005;17:265-88.

66 McMillan DW, Chavis DM. Sense of community: a definition and theory. J Community Psychol 1986;14:6-23.

67 Gusfield JR. The community: a critical response. New York: Harper Colophon, 1975.

68 Ahlbrant RS, Cunningham JV. A new public policy for neighborhood preservation. New York: Praeger, 1979.

69 Palencia L, Vásquez-Vera H, Borrell C. Problems in dealing with the mortgage and its effect on health: a study with people on the platform affected by the mortgage [TRANSLATED]. Barcelona Societat 2016;20:1-12

70 Olsen JR, Dundas R, Ellaway A. Are changes in neighbourhood perceptions associated with changes in self-rated mental health in adults? A 13-year repeat cross-sectional study, UK. Int J Environ Res Public Health 2017:14:1473.

71 Roberts JD, Tehrani SO. Environments, behaviors, and inequalities: reflecting on the impacts of the influenza and coronavirus pandemics in the United States. Int J Environ Res Public Health 2020;17:4484

72 MacDonald JM, Stokes RJ, Cohen DA, et al. The effect of light rail transit on body mass index and physical activity. Am J Prev Med 2010;39:105-12.

73 Humpel N, Marshall AL, Leslie E, et al. Changes in neighborhood walking are related to changes in perceptions of environmental attributes. Ann Behav Med 2004;27:60-7.

74 McDonald SC. Does gentrification affect crime rates? Crime Justice 1986;8:163-201.

75 Slogan W. Fear of crime and neighborhood change. The University of Chicago, 1986. Available: http://www.skogan.org/files/Fear.of. Crime.and.Neighborhood.Change.1986.pdf [Accessed 6 Jul 2019].

76 Taylor RB, Covington J. Community structural change and fear of crime. Soc Probl 1993;40:374-97.

77 Fayyad A. The presence of justice: the criminalization of gentrifying neighborhoods. The Atlantic, 2017. Available: https://www. theatlantic.com/politics/archive/2017/12/the-criminalization-ofgentrifying-neighborhoods/548837/ [Accessed 8 Sep 2019].

78 Mujahid MS, Sohn EK, Izenberg J, et al. Gentrification and displacement in the San Francisco Bay area: a comparison of measurement approaches. Int J Environ Res Public Health 2019;16:2246.

79 US.Census Reporter. Quick facts - prince George's County, Maryland. [online]. Available: https://www.census.gov/quickfacts/ fact/table/princegeorgescountymaryland/PST040217 [Accessed 2 Aug 2018].

80 Bennett WL, Cheskin L. Advancing research methods for evaluation of natural experiments in obesity prevention. Johns Hopkins University evidence-based practice center. Available: https:// www.jhsph.edu/research/centers-and-institutes/health-servicesoutcomes-research/ images/Materials/Advancing\%20Research\% 20Methods\%20for\%20Evaluation\%20of\%20Natural\% 20Experiments\%20in\%200besity\%20Prevention.pdf [Accessed 6 Jul 2019].

81 MacMillan F, George ES, Feng X, et al. Do natural experiments of changes in neighborhood built environment impact physical activity and diet? A systematic review. Int J Environ Res Public Health 2018;15:217.

82 Kärmeniemi M, Lankila T, Ikäheimo T, et al. The built environment as a determinant of physical activity: a systematic review of longitudinal studies and natural experiments. Ann Behav Med 2018:52:239-51.

83 Saelens BE, Vernez Moudon A, Kang B, et al. Relation between higher physical activity and public transit use. Am J Public Health 2014;104:854-9.

84 Brown BB, Werner CM. Before and after a new light rail stop: resident attitudes, travel behavior, and obesity. J Am Plan Assoc 2008;75:5-12.

85 Brown BB, Werner CM. A new rail stop: tracking moderate physical activity bouts and ridership. Am J Prev Med 2007;33:306-9.

86 Miller HJ, Tribby CP, Brown BB, et al. Public transit generates new physical activity: evidence from individual GPs and accelerometer data before and after light rail construction in a neighborhood of salt lake City, Utah, USA. Health Place 2015;36:8-17.

87 Brown BB, Werner CM, Tribby CP, et al. Transit use, physical activity, and body mass index changes: objective measures associated with complete street Light-Rail construction. Am J Public Health 2015;105:1468-74.

88 Hong A, Boarnet MG, Houston D. New light rail transit and active travel: a longitudinal study. Transportation Research Part A: Policy and Practice 2016;92:131-44.

89 Maryland Transit Administration. Frequently asked questions: about the purple line. Available: https://www.purplelinemd.com/ about-the-project/faqs\#will-the-entire-16-2-mile-purple-line-openat-once-or-will-segments-open-when-ready [Accessed 10 Jan 2020]

90 Maryland Transit Administration. Connecting people and places: purple line progress. vol 20 Newsletter-Spring/Summer 2016, 2016. Available: http://www.purplelinemd.com/images/archive/ newsletters/Purple\%20Line\%20Newsletter\%202016-06-03.pdf [Accessed 15 Sep 2018]

91 Roberts JD, Hu M, Saksvig BI, et al. Examining the influence of a new light rail line on the health of a demographically diverse and understudied population within the Washington, D.C. metropolitan area: a protocol for a natural experiment study. Int $J$ Environ Res Public Health 2018:15:333. 
92 El-Geneidy A, Grimsrud M, Wasfi R, et al. New evidence on walking distances to transit stops: identifying redundancies and gaps using variable service areas. Transportation 2014;41:193-210.

93 Daniels R, Mulley C. Explaining walking distance to public transport: the dominance of public transport supply. J Trans Land Use 2016;6.

94 Zhao J, Deng W. Relationship of walk access distance to rapid rail transit stations with personal characteristics and station context. $J$ Urban Plan Dev 2013;139:311-21.

95 Jiang Y, Christopher Zegras P, Mehndiratta S. Walk the line: station context, corridor type and bus rapid transit walk access in Jinan, China. J Transp Geogr 2012;20:1-14.

96 O'Sullivan S, Morrall J. Walking distances to and from light-rail transit stations. Transp Res Rec 1996;1538:19-26.

97 Durand CP, Tang X, Gabriel KP, et al. The association of trip distance with walking to reach public transit: data from the California household travel survey. J Transp Health 2016;3:154-60.

98 Alshalalfah BW, Shalaby AS. Case study: relationship of walk access distance to transit with service, travel, and personal characteristics. J Urban Plan Dev 2007;133:114-8

99 Weinstein Agrawal A, Schlossberg M, Irvin K. How far, by which route and why? A spatial analysis of pedestrian preference. J Urban Des 2008;13:81-98.

100 Pew Research Center. Mobile fact sheet, 2019. Available: https:// www.pewinternet.org/fact-sheet/mobile/ [Accessed 9 Sep 2019].

101 Alesco Data Group. Alesco data. Available: http://www.alescodata. com/data/master-consumer-db/ [Accessed 16 Sep 2018]

102 Fincham JE. Response rates and responsiveness for surveys, standards, and the journal. Am J Pharm Educ 2008;72:43

103 Roberts JD, Knight B, Ray R, et al. Parental perceived built environment measures and active play in Washington DC metropolitan children. Prev Med Rep 2016;3:373-8.

104 DeVylder J, Fedina L, Jun H-J. The neighborhood change and Gentrification scale: factor analysis of a novel self-report measure. Soc Work Res 2019;43:279-84.

105 Chavis DM, Lee KS, Acosta JD. The sense of community (SCI) revised: the reliability and validity of the SCl-2. paper presented at the 2nd International community psychology Conference, Lisboa, Portugal, 2008.

106 A Community Science Project. Sense of community (SCI), 2007 Available: https://www.senseofcommunity.com/soc-index/ [Accessed 23 Apr 2020].

107 Kessler RC, Andrews G, Colpe LJ, et al. Short screening scales to monitor population prevalences and trends in non-specific psychological distress. Psychol Med 2002;32:959-76.

108 Cerin E, Saelens BE, Sallis JF, et al. Neighborhood environment Walkability scale: validity and development of a short form. Med Sci Sports Exerc 2006;38:1682-91.

109 WalkScore. WalkScore. Available: https://www.walkscore.com [Accessed 15 Sep 2018]

110 Roberts JD, Ray R, Biles AD, et al. Built environment and active play among Washington DC metropolitan children: a protocol for a cross-sectional study. Arch Public Health 2015;73:22.

111 Kozlowski-Serra M, Smith J, Glazener E, et al. Tracking enforcement rates in prince George's County, MD 2006-2018. A report of the research network on Misdemeanor Justice, 2019. Available: https:// datacollaborativeforjustice.org/wp-content/uploads/2020/04/RNMJPrince-Georges-Report.pdf [Accessed 26 Jun 2020].
112 Preacher KJ. Latent growth curve modeling. Los Angeles, CA: SAGE, 2008.

113 Chou C-P, Yang D, Pentz MA, et al. Piecewise growth curve modeling approach for longitudinal prevention study. Comput Stat Data Anal 2004;46:213-25.

114 Little TD, Card NA, Preacher KJ. Modeling longitudinal data from research on adolescence. In: Lerner R, Steinberg L, eds. Handbook of adolescent psychology. 3rd edn. Hoboken, NJ: Wiley, 2009.

115 Duncan TE, Duncan SC. An introduction to latent growth curve modeling. Behav Ther 2004;35:333-63.

116 Curran PJ, Bauer DJ, Willoughby MT. Testing main effects and interactions in latent curve analysis. Psychol Methods 2004;9:220-37.

117 Cheong J, Mackinnon DP, Khoo ST. Investigation of mediational processes using parallel process latent growth curve modeling. Struct Equ Modeling 2003;10:238-62.

118 Gibbons J, Barton MS. The association of minority self-rated health with black versus white Gentrification. J Urban Health 2016;93:909-22.

119 Izenberg JM, Mujahid MS, Yen IH. Health in changing neighborhoods: a study of the relationship between gentrification and self-rated health in the state of California. Health Place 2018;52:188-95.

120 Knaap GJ, Ding C, Hopkins LD. Do plans matter?: the effects of light rail plans on land values in station areas. J Plan Educat Res 2001;21:32-9.

121 National Public Radio. How to limit Gentrification along the purple line, according to housing advocates. National public radio. WAMU 88.5, 2019. Available: https://www.npr.org/local/305/2019/12/ 12/787445618/how-to-limit-gentrification-along-the-purple-lineaccording-to-housing-advocates [Accessed 24 Feb 2020].

122 Watson B, Robinson DHZ, Harker L, et al. The inclusion of AfricanAmerican study participants in web-based research studies: viewpoint. J Med Internet Res 2016;18:e168.

123 National Institutes of Health. Pathways to prevention workshop: methods for evaluating natural experiments in obesity. December 5-6, 2017 in Natcher conference center, NIH campus, Bethesda, Maryland, 2017. Available: https://prevention.nih.gov/p2pworkshop/2017/methods-evaluating-natural-experiments-obesity [Accessed 11 Nov 2017]

124 Terrell F, Moseley KL, Mosley KL, et al. The relationship between motivation to volunteer, gender, cultural mistrust, and willingness to donate organs among blacks. J Natl Med Assoc 2004;96:53-60.

125 American Immigration Council. Immigrants in Maryland, 2017. Available: https://www.americanimmigrationcouncil.org/research/ immigrants-in-maryland [Accessed 21 Sep 2018].

126 DLS. Overview of Hispanic community in Maryland. Department of legislative services office of policy analysis. Annapolis, Maryland, 2008. Available: http://dls.maryland.gov/pubs/prod/ InterGovMatters/Demog/Overview-of-Hispanic-Community.pdf [Accessed 21 Sep 2018].

127 O'Sullivan F. How to safely travel on mass transit during coronavirus. Bloomberg CityLab, 2020. Available: https://www. bloomberg.com/news/articles/2020-05-27/trains-planes-andbuses-how-to-avoid-coronavirus [Accessed 30 Jun 2020].

128 Costa MF. Health belief model for coronavirus infection risk determinants. Rev Saude Publica 2020;54:47. 